\title{
Human Behavior in Downtown Public Spaces during Cooling Periods in Winter Cities
}

\author{
Minori Kusaka, Tsuyoshi Setoguchi, Norihiro Watanabe, Zhiming Guo and Anasutasiia Paukaeva \\ Faculty of Engineering, Graduate School of Hokkaido University, Sapporo, 060-8628, Japan
}

\begin{abstract}
There is an urban design problem that outdoor public spaces are not used for long periods of time within a year due to coldness and snow cover in cities with severe winter climates (winter cities). Therefore, an urban design that promotes activities in these spaces is required for winter cities. The purpose of this paper is to clarify the relationship between outdoor environmental conditions and the behaviors of people in outdoor public spaces. This six-month study conducted a field survey in six kinds of public spaces in downtown Sapporo and analyzed the changes of microclimates and sitting behaviors in these spaces. The analysis revealed that sitting behaviors decreased with temperature drops during the cooling period $\left(20{ }^{\circ} \mathrm{C}-8{ }^{\circ} \mathrm{C}\right)$, that sunlight could suppress the reduction in the number of sitting behaviors, and that wind speed could suppress the reduction in the duration of sitting behaviors.
\end{abstract}

Key words: Winter city, microclimate, public space, urban open space, actual usage, field measurement, outdoor environment.

\section{Introduction}

\subsection{Purpose of the Research}

Today, urban areas have become places of life, and more than half of the world's population live in such areas. Providing comfortable spaces where people can spend their time in urban areas is an important issue in urban planning. Specifically, outdoor public spaces are emphasized as places of rest, places to walk in the city, and places to perform creative activities and to interact with people.

However, in cities that experience severe winters (winter cities), their cold climates lower comfort and decrease the level of activity in outdoor public spaces. The season when people can enjoy outdoor public spaces in these cities is shorter than that in warm cities. Therefore, a different urban design approach must be adopted for winter cities [1, 2]. It is particularly important to design outdoor public spaces to suppress their reduction in usage with lowering temperatures. Outdoor public spaces in downtown areas are often planned adjacent to redevelopments involving

Corresponding author: Minori Kusaka, master student; research field: urban design for winter cities. E-mail: m.kusaka7905@gmail.com. high-rise buildings. This strongly affects public spaces, as buildings with large volumes elicit large localized changes in an urban area's environmental conditions. So, in order to design the environment of outdoor public spaces, it is necessary to consider the surrounding high-rise buildings.

Therefore, the purpose of this study is to clarify the relationship between the human behaviors and the outdoor environment in order to suggest an outdoor public space design that can suppress reduced usage at lower temperatures in winter cities.

\subsection{Previous Studies}

Many researchers have discussed the composition of downtown public spaces relative to human behaviors and spatial recognition. For example, Taguchi et al. [3] clarified spatial compositions based on people's behaviors. They aimed to clarify the perception of people in urban planning and analyzed the formation of impressions through the recognition of human behaviors.

Regarding the influence of the outdoor environment on the spatial compositions of downtown public spaces, Bosselmann et al. [4] investigated that future 
urban spatial composition affects ground-level sunlight, wind speed, and thermal comfort. Bosselmann et al. [5, 6] also studied downtown San Francisco, in the United States, and showed that new developments involving high-rise buildings caused environmental problems because of changes in the wind and sunlight conditions in the surrounding areas. They insisted on the importance of urban design with a framework to counter regional climatic conditions.

Zacharias et al. [7] insisted on the importance of knowing how people respond to microclimatic conditions. They used actual measurements to clarify the relationship between microclimates such as temperature and sunlight and people's usage behaviors.

Eliasson et al. [8] revealed that space components affect certain microclimates, and as a result, microclimates affect people's perceptions and behaviors. There are few other studies that analyze the relationship between spatial compositions, outdoor environments, and people's behaviors simultaneously. However, there are some studies that focus on downtown areas in the cold season.

Based on the above, this study focuses on the downtown public spaces of winter cities and analyzes the relationship between the three elements of spatial composition, outdoor environment, and people's behavior.

\section{Methods}

\subsection{Target Areas}

The city of Sapporo is included in the winter zone, where the coldness is one of the most severe in the world. The winter zone is defined as the area within $0{ }^{\circ} \mathrm{C}$ isotherm in January [9]. Sapporo has a particularly large population among cities located in the winter zone around the world. A large-scale redevelopment is ongoing in the central part of the city. We focused on this part and selected three target areas from districts that had privately owned public spaces. These areas were chosen because there were more people behaviors than in other areas. The survey was conducted on six public spaces in the three target areas. Each of the six public spaces had some sitting places for people to stay, and had a different spatial composition depending on the arrangement of buildings and the condition of connections to the sidewalk. Fig. 1 summarizes the characteristics of the spatial compositions of each public space.

\subsection{Field Survey Method}

In this research, we focused on the relationship between people's behavior and the characteristics of the environmental conditions in each target area. The survey days were selected between September 2016 and May 2017 with one day in a month without snow cover (Table 1). There were eight survey days in all. Each survey was conducted from 12:00 p.m. to 1:00 p.m., when the most sitting behaviors were expected. All of the days were set on holidays in order to eliminate restrictions on sitting time due to office workers' lunchtime and other breaks, as much as possible. There were two days when the survey could not be conducted depending on the target area. On April 23, the survey could not be conducted in public spaces $\mathrm{C}-1$ and $\mathrm{C}-2$, because there was an event in target area C. On April 29, the survey was not conducted in public space $\mathrm{B}$, because the adjacent building was closed, and this was considered to affect the number of sitting groups.

Outdoor environmental factors were measured on three parameters: temperature, wind speed, and sunlight. Temperature and wind speed were measured for one minute every 15 minutes at the target area measuring points (see Fig. 1). This was done four times in total, and the meteorological data on Sapporo City by JMA (Japan Meteorological Agency) data for each survey date [10] were also obtained. For the measurements, a thermo-anemometer (Kestrel 4500, Nielsen Kellerman Co., United States) was used. The situation of the sunlight was recorded by drawing a shade line. 


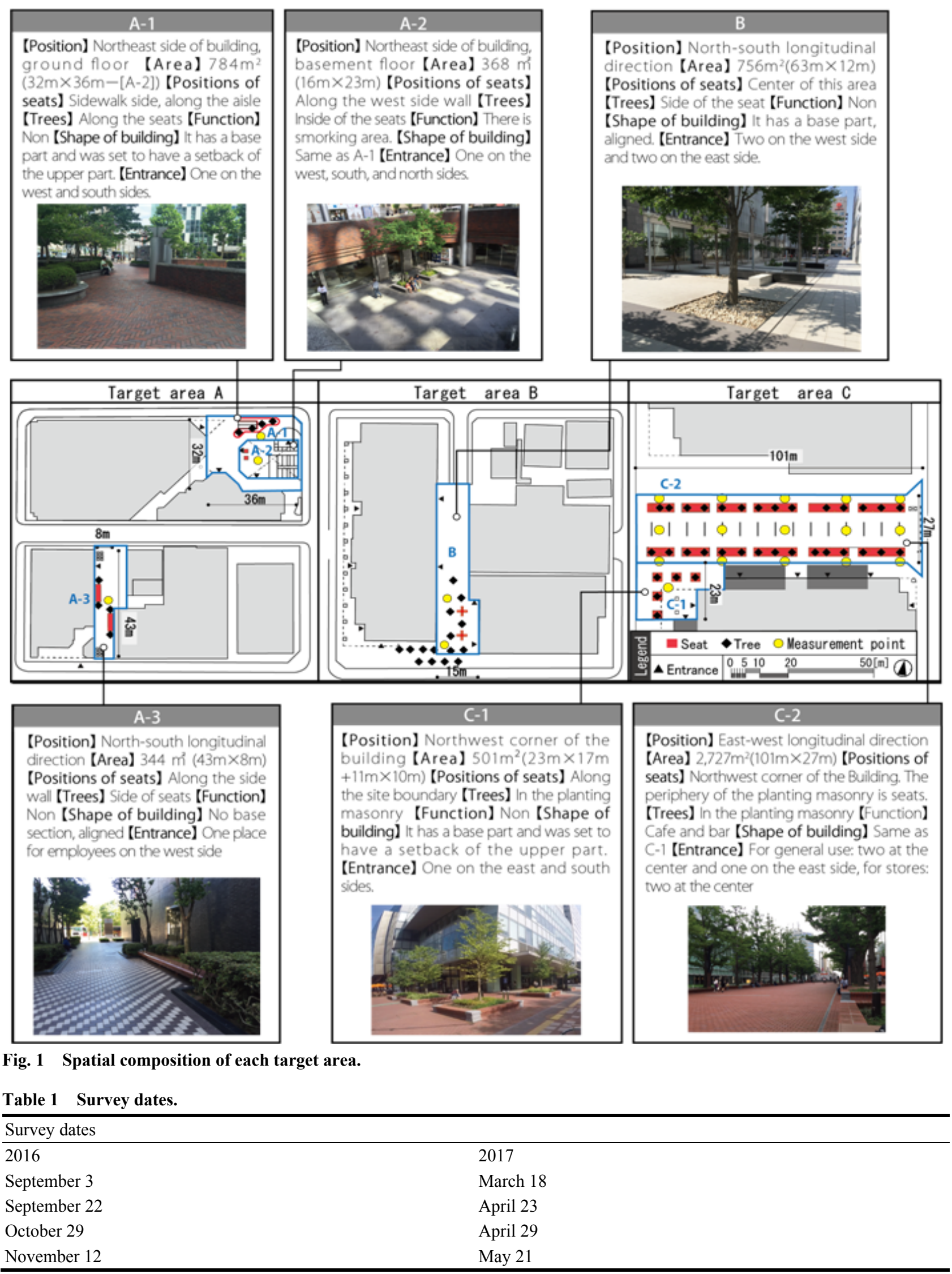


According to Gehl [11], the activity of people is evaluated by the product of "the number of events" and "the duration". The larger the product, the better the activity in a public space is evaluated. Therefore, this field survey measured the number of sitting groups as "the number of events" and the sitting time as "the duration". In addition, the sitting position of each sitting group was recorded by plotting on a ground plan view. All behaviors during the survey were recorded using a time-lapse camera (Brinno TLC 200 Pro, Brinno Co., TWN).

\subsection{Analysis Method}

The relationship between sitting behaviors and each outdoor environmental element was analyzed based on the data obtained from the survey. The number of sitting groups varied depending on the size and location of each public space. For the analysis, the rate of change in the number of sitting groups from that on the highest temperature day was calculated for each public space. This was done in order to compare the influence of the difference in outdoor environment on the number of sitting groups. The average time of all sitting groups per hour was also analyzed. Fig. 2 shows analysis method of sitting behaviors.

\section{Results of the Survey}

First, the macro weather conditions of the Sapporo area on each survey day were obtained from weather data of JMA (Table 2).

Next, the measured data were plotted (see Fig. 3). In this graph, the section indicated by a dotted line is the section where the survey was not conducted in the public space. Of all the survey days, the highest temperature was $25.1{ }^{\circ} \mathrm{C}$ on September 3, and the lowest temperature was $5.3{ }^{\circ} \mathrm{C}$ on March 18. There were no significant differences among the target areas.

The surrounding building volumes influenced wind speed, so large differences of wind speed were seen for each public space. The public spaces with buildings on opposite sides (A-3, B, and C-2) were divided into those with high wind speeds $(\mathrm{B}, \mathrm{C}-2)$ and one with a low wind speed (A-3). The widths of the public open spaces and the heights of the adjacent buildings were considered to be factors for differences in wind speed.

In the public space surrounded by walls on all sides (A-2), the wind speed was low and steady. Compared with the other public spaces, there were variations in the wind speed in the spaces with buildings on two adjacent sides (A-1, C-1). The wind direction was also considered to be an influencing factor.

The proportions of the sunny areas to sitting surfaces of each public space were compared. A public space with a sunny area of more than half of its sitting surface was defined as "a public space with a



Fig. 2 Analysis method of sitting behavior.

Table 2 General meteorological data for Sapporo.

\begin{tabular}{lllllllll}
\hline Survey dates & $9 / 3$ & $9 / 22$ & $10 / 29$ & $11 / 12$ & $3 / 18$ & $4 / 23$ & $4 / 28$ & $5 / 21$ \\
\hline Temperature $\left[{ }^{\circ} \mathrm{C}\right]$ & 25.1 & 18.6 & 5.5 & 7.8 & 5.3 & 8.4 & 15.1 & 22.4 \\
Wind Speed $[\mathrm{m} / \mathrm{s}]$ & 6.5 & 5.4 & 10.4 & 0.9 & 5.2 & 3.3 & 4.9 & 2.9 \\
Weather & Cloudy & Cloudy & Sunny & Sunny & Sunny & Sunny & Sunny & Cloudy \\
\hline
\end{tabular}




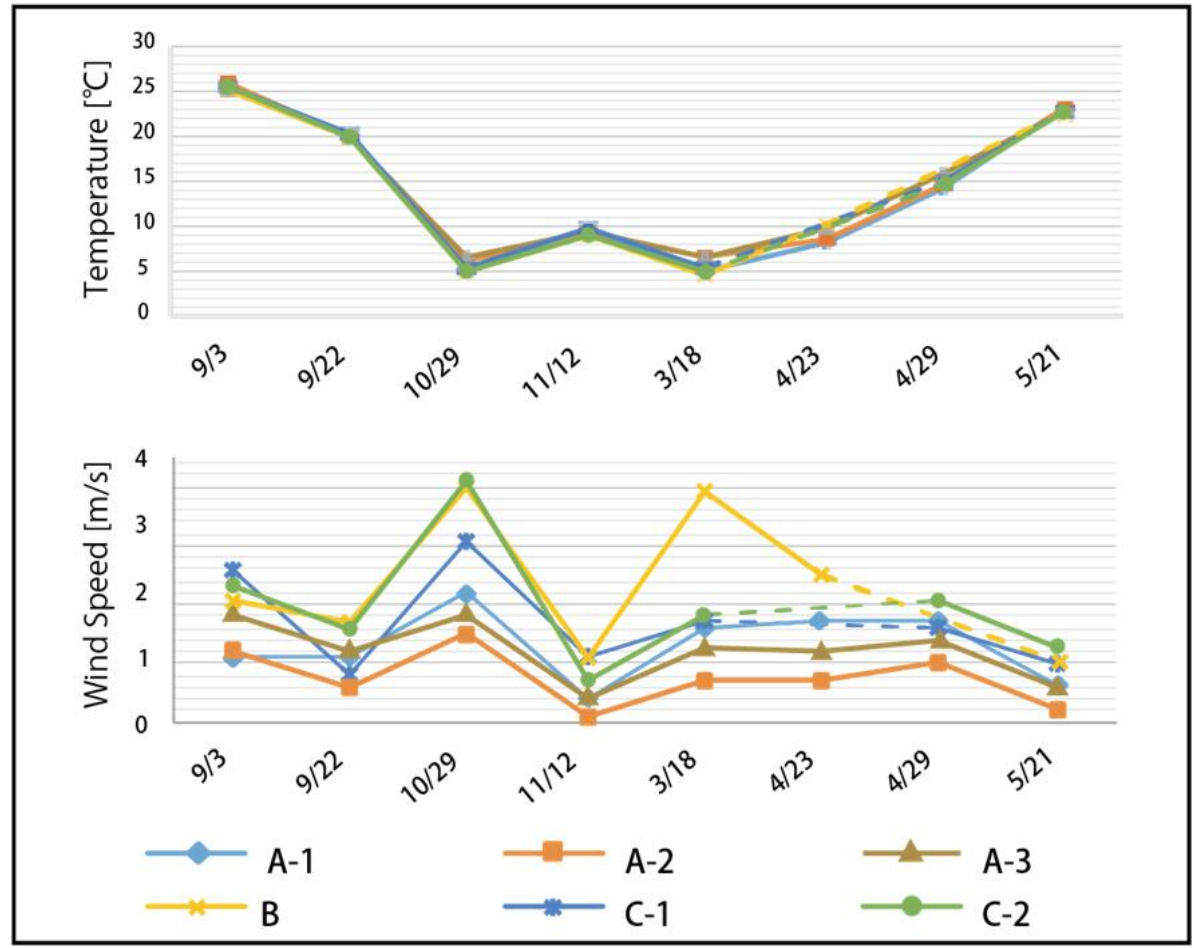

Fig. 3 Microclimate data for each public space.

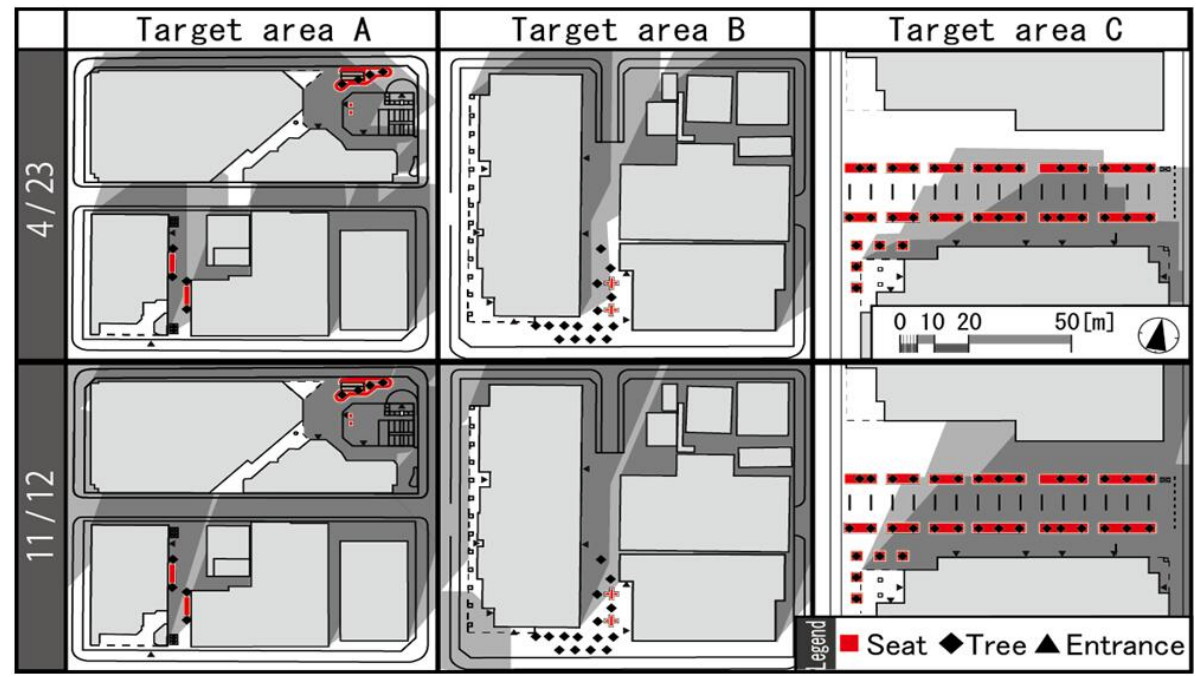

Fig. 4 Location of sunny places in each public space.

large sunny area". On the other hand, a public space with a sunny area of less than half of its sitting surface was defined as "a public space with a small sunny area" (see Fig. 4).

From the above, the six public spaces were classified based on the environmental conditions with respect to sunlight and wind speed. There were large differences, depending on the public space (Table 3 ).

Next, the sitting behaviors were organized, and the sitting position of each user and the distributions of sitting behavior (Fig. 5) were plotted. It was found that places around the entrances to buildings were the most used in all of the public spaces.

\section{Analysis}

\subsection{Impact of Temperature on Sitting Behaviors}

The changes in the number of sitting groups and the average sitting time caused by the lowering of the 
Table 3 Classification of public spaces.

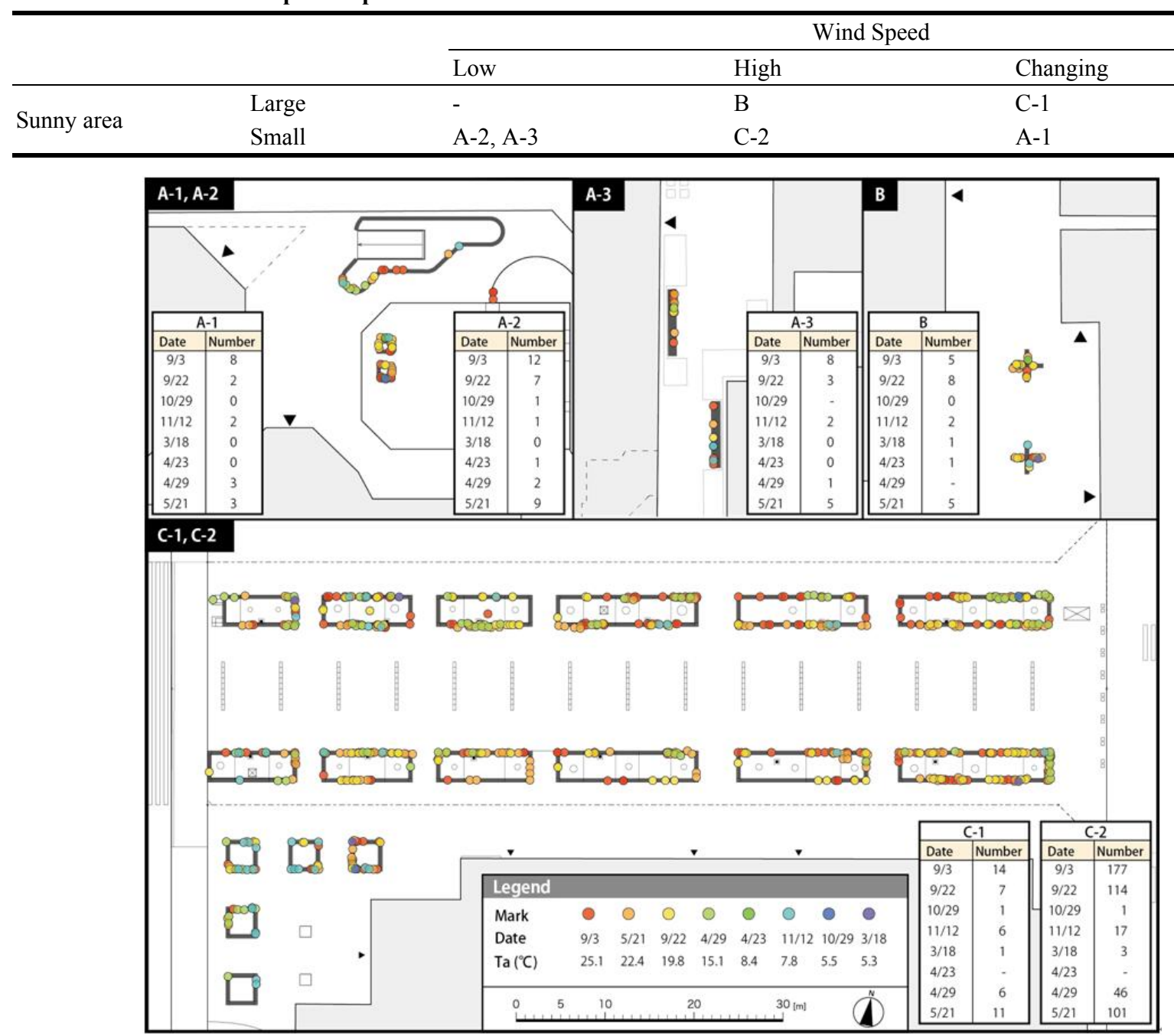

Fig. 5 Plot of people sitting on each survey day.

temperature in each public space were analyzed. At around $20{ }^{\circ} \mathrm{C}$ or higher, the influence of the environment was barely observed for both the number of sitting groups and the average sitting time. This was considered to be a comfortable temperature for sitting, and the spaces were used freely. Also, at around $5{ }^{\circ} \mathrm{C}$ or lower, the sitting behaviors in each public space were very few, almost not seen. That was assumed to be a result of the influence of low temperature (see Fig. 6).

In the temperature zone (cooling period) from $20^{\circ} \mathrm{C}$ to $8{ }^{\circ} \mathrm{C}$, there were variations in how the sitting behavior changed depending on the public space. It was inferred that environmental factors such as sunlight and wind speed, which varied depending on the public space, influenced the increase and decrease of sitting behaviors.

\subsection{Impact of Sunlight on Sitting Behaviors}

Fig. 7 shows the shade lines at 12:30 p.m. and the sitting positions during one hour from 12:00 p.m. to 1:00 p.m. on each investigation day at the target site C. The sitting places in the plaza are evenly used on investigation days with temperatures of $15{ }^{\circ} \mathrm{C}$ or more. However, on investigation day with a temperature of $7.8{ }^{\circ} \mathrm{C}$, the number of people sitting in the shade is fewer than the number of people sitting in the sun. It can be said that the areas that are more exposed to sun 


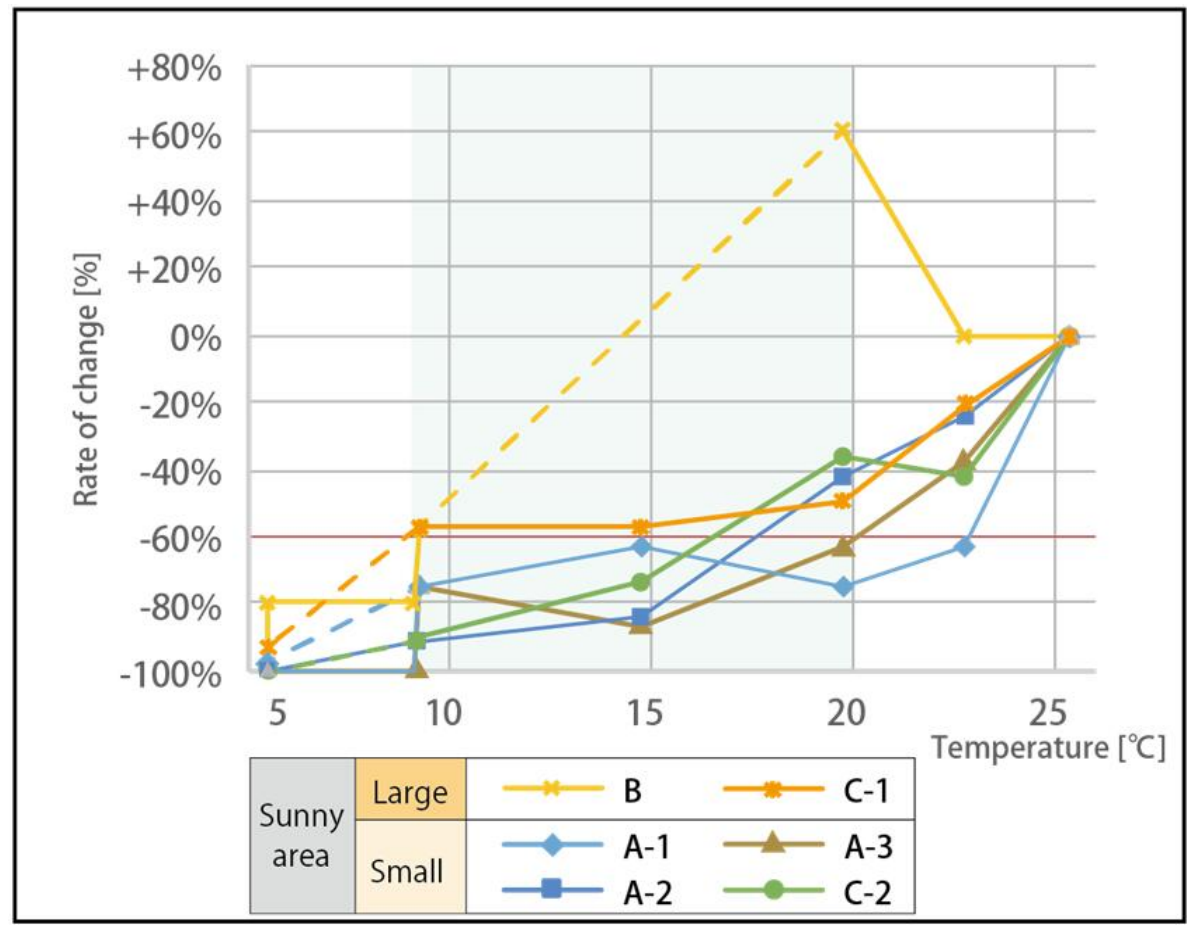

Fig. 6 Analysis of the relationship between human activity and temperature.

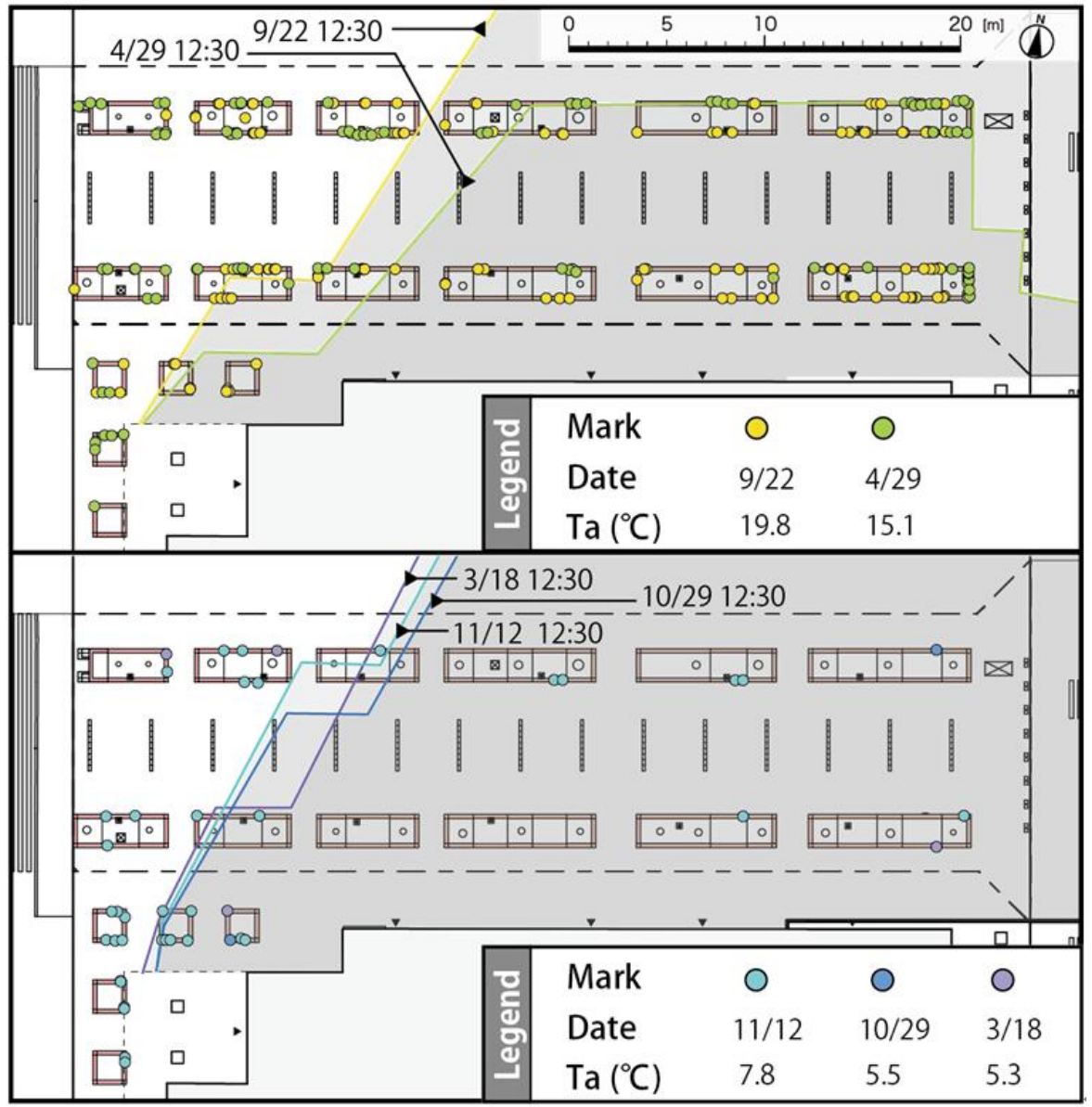

Fig. 7 Plot of people's sitting locations in sunny places in the target area $\mathrm{C}$. 


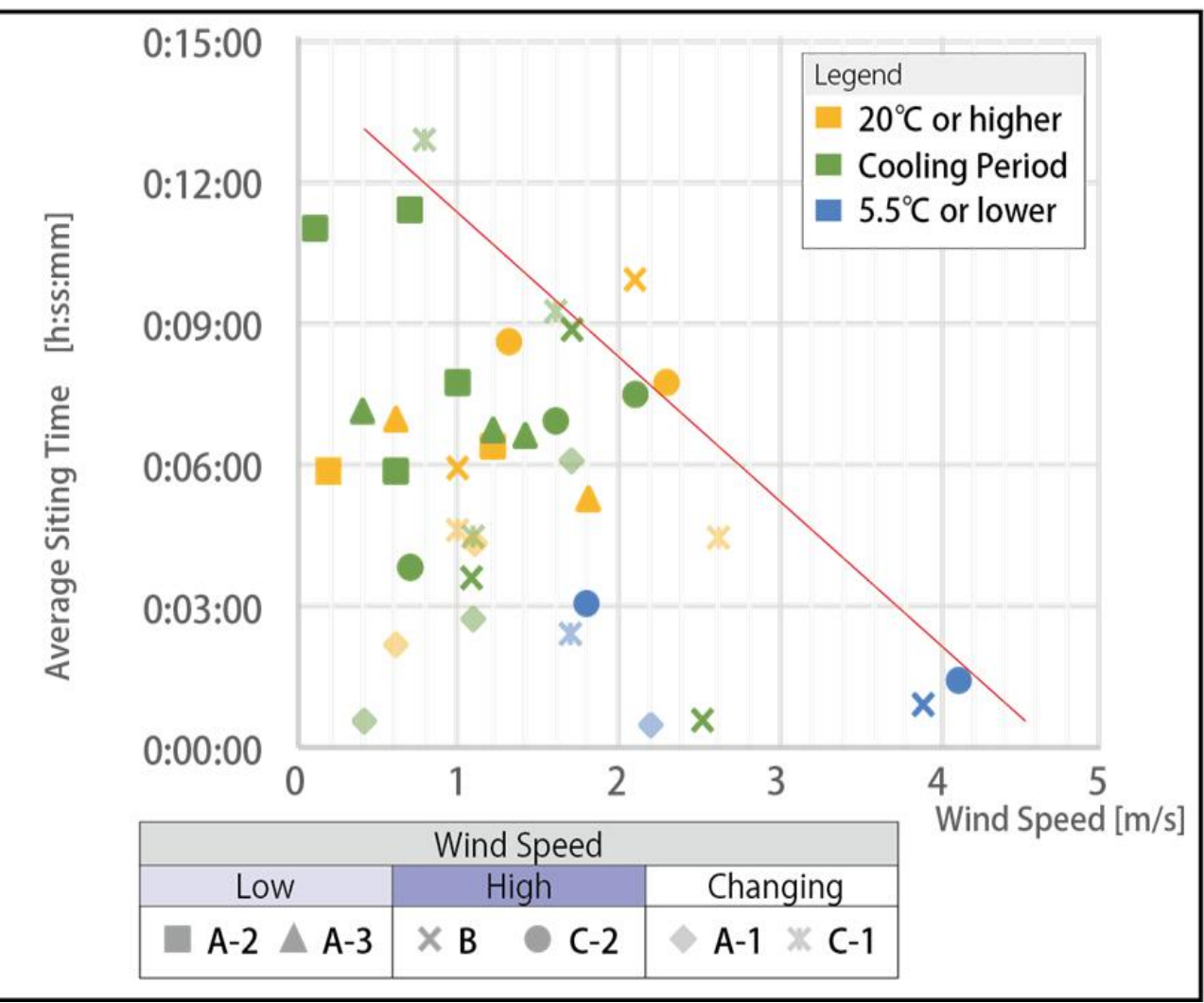

Fig. 8 Analysis of the relationship between average sitting time and wind speed.

are preferred for sitting behaviors during the cooling period. On the investigation day with a temperature around $5{ }^{\circ} \mathrm{C}$, sitting behavior is rarely seen regardless of sunlight. Regarding the number of sitting groups, the public spaces with a large sunny areas $(\mathrm{B}, \mathrm{C}-1)$ have a higher rate of sitting groups at $7.8{ }^{\circ} \mathrm{C}$ (approximately 40\%), compared with the rate for the public space with a small sunny area (see Fig. 6, rate of change). According to the results, we can assume that a sunny place is preferred for sitting during the cooling period. Additionally, a decrease in the number of sitting groups is observed for the public spaces that have a large sunny area. Therefore, sunlight is the critical factor that induces sitting behaviors. Moreover, the average sitting time does not show a difference relative to the sunny area. It is believed that sunlight has no effect on the time of remaining in a sitting place.

\subsection{Impact of Wind Speed on Sitting Behaviors}

There is no difference in the decrease in the number of sitting groups relative to the trend of the wind speed. Fig. 8 shows the relationship between the average sitting time and wind speed. When the wind speed is lower, the average sitting time is longer, however, when the wind speed is higher, the average sitting time is shorter during the cooling period. In public spaces with low wind speeds (A-2, A-3), the average sitting time during the cooling period is similar to that at $20{ }^{\circ} \mathrm{C}$ or more. The maximum value of the average sitting time decreased as the wind speed increased. It turned out that the public spaces with low wind speeds were used regardless of the temperature. However, when the temperature decreases under approximately $5{ }^{\circ} \mathrm{C}$, the sitting behavior tends to disappear. Moreover, the average sitting time for public spaces with low wind speeds is longer than that for public spaces with high wind speeds. Therefore, it is assumed that people keep sitting longer in public spaces with lower wind speeds versus those with higher wind speeds, even if the temperature drops. 


\section{Conclusion}

This study conducted a field survey and analyzed the relationship between the outdoor environment and sitting behaviors in outdoor public spaces in downtown Sapporo.

At around $20^{\circ} \mathrm{C}$ or higher, the outdoor environment did not affect the number, time or location of sitting behaviors, and many sitting behaviors were observed in the public spaces. In addition, almost no sitting behaviors were observed in public spaces at temperatures below $5{ }^{\circ} \mathrm{C}$. During the cooling period (around $20^{\circ} \mathrm{C}$ to $8^{\circ} \mathrm{C}$ ), the sitting behaviors decreased with lowering temperatures. However, microclimates influenced by sunlight and wind speed affected the reduction in the number of sitting groups, sitting time, and sitting behaviors. Therefore, it is important to control the microclimates of the outdoor public spaces and to create desirable outdoor environments in order to promote sitting behaviors during the cooling period.

The reduction in the number of sitting groups was suppressed in public spaces with large sunny areas until the temperature dropped to approximately $8{ }^{\circ} \mathrm{C}$. It appeared that a situation with sunlight was a trigger for sitting behaviors. In the public spaces with low wind speeds, the average sitting time was maintained even as the temperature decreased. As the wind speed increased, the average sitting time decreased. Furthermore, the sitting time could be lengthened by reducing the wind speed.

Based on the above results, a public space design that secures plenty of sunny area and reduces wind speed can suppress the reduction in sitting behaviors during the cooling period and extend the duration of use of outdoor public spaces in winter cities.

This study has clarified the environmental conditions in outdoor public spaces to promote sitting behaviors in the cooling period. In future research, it will be necessary to study the relationship between outdoor environmental conditions and outdoor public spatial compositions, including the surrounding building designs. This will allow for the development of urban design guidelines that create desirable environments to promote human activity in outdoor public spaces in winter cities.

\section{Acknowledgments}

This work was supported by JSPS KAKENHI Grant Number 25249082.

\section{References}

[1] Pressman, N. 1995. Northern Cityscape: Linking Design to Climate. Yellowknife: Winter Cities Association.

[2] Ebrahimabadi, S., Nilsson, K. L., and Johansson, C. 2015. "The Problems of Addressing Microclimate Factors in Urban Planning of the Subarctic Regions." Environment and Planning B: Planning and Design 42 (March): 415-30.

[3] Taguchi, Y., and Gotou, H. 2011. "The Impression of Human Assemblage in Station Square: The Analysis on Landscape Element Based on the Survey of Human Activity." Summaries of Technical Papers of Annual Meeting. 2011 (July): 641-42. (in Japanese)

[4] Bosselmann, P., and Arens, E 1990. "Sun, Wind, and Pedestrian Comfort: A Study of Toronto's Central Area." Center of Environmental Design Research, University of California.

[5] Bosselmann, P., Flores, J., Gray, W., Priestley, T., Anderson, R., Arens, E., and Kim, J. J. 1984. Sun, Wind, and Comfort: A Study of Open Spaces and Sidewalks in Four Downtown Areas. Berkeley, CA: Center for Environmental Design, University of California.

[6] Arens, E., and Bosselmann, P. 1989. "Wind, Sun and Temperature-Predicting the Thermal Comfort of People in Outdoor Spaces." Building and Environment 24 (4): 315-20.

[7] Zacharias, J., Stathopoulos, T., and Wu, H. 2001. "Microclimate and Downtown Open Space Activity." Environment and Behavior 39(September): 660-84.

[8] Eliasson, I., Knez, I., Westerberg, U., Thorsson, S., and Lindberg, F. 2007. "Climate and Behavior in a Nordic City." Landscape and Urban Planning 82 (August): 72-84.

[9] The Northern Regions Center Research Div. 1988. The Business of Winter. Sapporo: the Northern Regions Center.

[10] Japan Meteorological Agency. 2017. "Kako no Kishou data Kensaku (Search Past Weather Data). Accessed December 22, 2017. http://www.data.jma.go.jp/obd/stats/ 
etrn/index.php (in Japanese)

[11] Gehl, J. 1990. Okugaikukan no Seikatu to Design (Life between Buildings). Tokyo: Kajima Institute Publishing. (in Japanese) 